\title{
Determination and Application of Comprehensive Specific Frictional Resistance in Heating Engineering
}

\author{
Yanan Tian, ${ }^{1}$ Haosen Wang, ${ }^{2}$ Yongjiang Shi $\left(D,{ }^{1}\right.$ Jiayu Rong $\mathbb{D}^{1}$, \\ Zhenhua Ma $(1),{ }^{2}$ and Cong Xie ${ }^{2}$ \\ ${ }^{1}$ College of Energy and Environmental Engineering, Hebei Institute of Architecture and Civil Engineering, Zhangjiakou, \\ Hebei 075000, China \\ ${ }^{2}$ College of Mathematics and Physics, Hebei Institute of Architecture and Civil Engineering, Zhangjiakou, Hebei 075000, China \\ Correspondence should be addressed to Yongjiang Shi; yy1114916122@163.com
}

Received 9 July 2017; Revised 12 November 2017; Accepted 22 November 2017; Published 4 January 2018

Academic Editor: Andrea L. Facci

Copyright (C) 2018 Yanan Tian et al. This is an open access article distributed under the Creative Commons Attribution License, which permits unrestricted use, distribution, and reproduction in any medium, provided the original work is properly cited.

In this study, we analyze the deficiencies of specific frictional resistance in heating engineering. Based on economic specific frictional resistance, we put forward the concept of comprehensive specific frictional resistance, which considers the multiple factors of technology, economy, regulation modes, pipe segment differences, and medium pressure. Then, we establish a mathematical model of a heating network across its lifespan in order to develop a method for determining the comprehensive specific frictional resistance. Relevant conclusions can be drawn from the results. As an application, we have planned the heating engineering for Yangyuan County in China, which demonstrates the feasibility and superiority of the method.

\section{Introduction}

With the development of modern society, improvements in heating engineering have attracted attention. In the field of heating engineering, the specific frictional resistance refers to the resistance loss of pipe per meter [1, 2], which is very important in China. In this paper, we discuss specific frictional resistance during the designing or planning stage, when specific frictional resistance acts as an intermediary to select a suitable pipe diameter.

At present, studies mainly involve two aspects of specific frictional resistance: one is the weighted average specific frictional resistance; the other is economic specific frictional resistance. For a heating network with regulated change in flow rate at different stages, the specific frictional resistance undergoes a step change due to the change in flow rate. In order to measure and reflect this characteristic of the specific frictional resistance, weighted average specific frictional resistance is recommended for selecting pipe diameters. Hong [3] discussed the differences between weighted average frictional resistance and traditional specific frictional resistance and analyzed the power-saving effect by taking a heating network with flow rate regulation as an example. The economic specific frictional resistance is an ideal value relative to the specific frictional resistance from the economic perspective and is widely used in China at present. Ge et al. [4] established a mathematical model, which took the minimum cost of the heating network as the objective function, and discussed the relationship between the economic specific frictional resistance and the economic heating radius. Liu et al. [5] offered the concept of the new economic specific frictional resistance by establishing the transportation distance limit model and the transport energy consumption ratio model. Wang et al. [6] took the indoor heating horizontal single tube and vertical single tube system as examples to establish a mathematical model with minimum cost as the objective function, by which they obtained the economic specific frictional resistance under different conditions. $\mathrm{Li}$ et al. [7] studied the hydraulic calculation methods and the existing problems on the condensate pipe net, and they used the differential method to calculate the economic specific frictional resistance of the condensate pipe net. 
Through analysis of the various research [3-11] on specific frictional resistance, we identified problems related to the value of specific frictional resistance, as follows:

(i) In China, the value of specific frictional resistance used in engineering still follows the traditional economic specific frictional resistance value of $30 \sim 70 \mathrm{~Pa} / \mathrm{m}$, which was introduced by the former Soviet Union in the last century. With the rise in prices and changes in materials, this value is not applicable to the current state of practice in heating engineering.

(ii) The value of specific frictional resistance should be related to the regulation modes, which can bring about different changes in flow rate and medium temperature. However, the traditional model of economic specific frictional resistance treats the different regulation modes in the same way [3-11].

(iii) With the development of the central heating network, pipe networks have become more massive and complex, which has led to increasing differences among pipe segments. Thus, it is not suitable to use the same specific frictional resistance standard of $30 \sim 70 \mathrm{~Pa} / \mathrm{m}$ to determine the pipe diameter in a network system. Instead, each pipe segment should be differentiated. That is to say, each pipe segment should have a specific frictional resistance of its own [3-11].

(iv) The distribution of pressure in the pipes is now more complicated because of the mass and complexity of the pipe networks. It has a direct relationship to the value of specific frictional resistance whether the pressure meets the requirements. However, the value of traditional economic specific frictional resistance of $30 \sim 70 \mathrm{~Pa} / \mathrm{m}$ does not take into account the constraints of the medium pressure [3-11].

In order to solve the above problems, we propose the concept of comprehensive specific frictional resistance. It refers to a measure of resistance loss of pipe per meter that incorporates a number of related factors. By means of it, heating engineering applications can achieve better economic effects during their lifespan [12-14]. The related factors considered in this paper include technology, economy $[15,16]$, operation regulation modes $[17,18]$, pipe segment differences, and the medium pressure [19-22].

\section{The Mathematical Model}

In this section, we give the method for obtaining the value of comprehensive specific friction resistance as follows.

2.1. Factors Related to Comprehensive Specific Frictional Resistance Theory. Through the analysis of technology, economy, operation regulation modes, pipe segment differences, and the medium pressure in a heating system, we have drawn several conclusions about the comprehensive specific friction resistance model theory:

(i) Pipe Segment Differences. With pipe networks becoming massive and complex, the difference among pipe segments becomes more apparent. For example, it is common for the pipe diameter close to the heat source to be DN1400, while the pipe diameter can be reduced to DN200 at the user end point. This difference should not be ignored. In order to account for the differences among pipe segments, a single pipe segment is taken as an object in establishing the mathematical model in this paper. In this way, we get different values corresponding to different pipe segments.

(ii) Operation Regulation Modes. We take into account the influence of operation regulation modes on comprehensive specific frictional resistance due to the fact that different operation regulation modes incur different electricity consumption and different heat loss.

(iii) Medium Pressure. The value of comprehensive specific frictional resistance takes into account the medium pressure constraint, which can prevent heating accidents on the operational stage, such as pipe cracking or medium vaporization. In the following study, the medium pressure constraint is mainly embodied in the constraint conditions of the mathematical model.

(iv) Technology and Economy. The Present Value Cost is chosen as the objective function $[23,24]$ by analyzing the advantages and disadvantages of each economic effect evaluation index.

(v) Technology and Economy. The value of specific frictional resistance is sensitive to the factors of primary network construction fee (including civil engineering cost and pipe installation fee), electricity fee, and fuel cost across the lifespan of heating engineering application. These factors must be embodied in the mathematical model. Heat source construction fee, heat exchange station construction fee, thermal user fuel cost, water fee, maintenance cost, and labor wages are irrelevant factors that can be ignored in the mathematical model.

2.2. Establishment of the Objective Function. In this section, we establish the objective function taking the single segment $i$ as the object. The objective function is the Present Value Cost of pipe segment $i$ across the lifespan of $n$ years, and the cost includes civil engineering cost, pipe installation fee, electricity fee, and fuel cost.

For the different regulations, the civil engineering cost and the pipe installation fee are the same, but the electricity fee and fuel cost are different, because the heat load varies continuously during heating season. The following is the establishment process of the objective function.

2.2.1. The Civil Engineering Cost. Taking the directly buried laying method as an example, a set of data about pipe diameter $d$ and the corresponding civil engineering cost $m_{1}$ from Chinese markets is shown in Figure 1.

The fitted curve is $m_{1}=255.673 d^{2}+498.819 d+113.133$, whose $R$-squared value is as high as $99.95 \%$. Hence, the relationship between the civil engineering cost and the pipe diameter can be expressed by a quadratic polynomial, as follows:

$$
m_{1}=a_{1} d^{2}+b_{1} d+c_{1}
$$




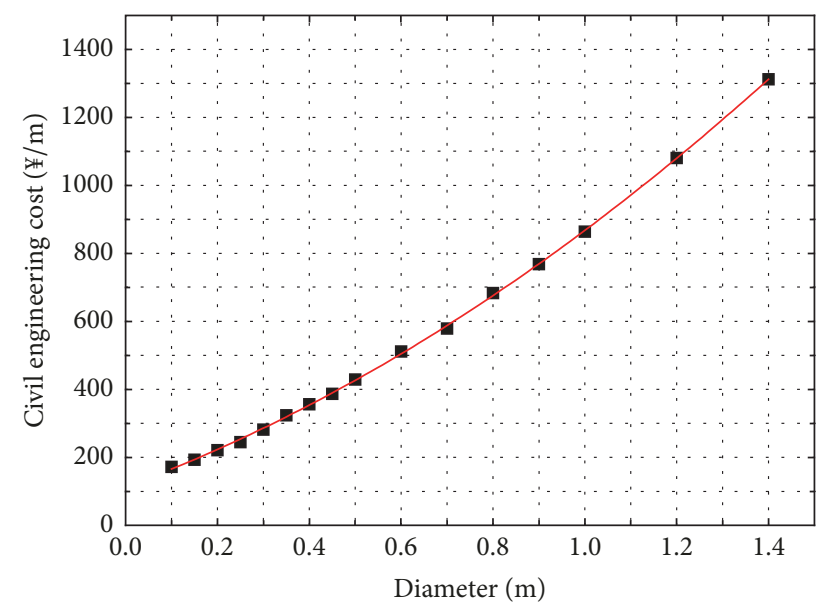

FIGURE 1: Fitting curve of heating pipe diameter and civil engineering cost.

where $m_{1}$ is the civil engineering cost of pipe with a diameter $d(¥ / \mathrm{m}), d$ is the pipe diameter $(\mathrm{m})$, and $a_{1}, b_{1}$, and $c_{1}$ are the fitting polynomial coefficients of civil engineering cost, which are determined by the specific situation.

As we all know, the Darcy-Weisbach Formula is

$$
h_{f}=\lambda \frac{l}{d} \cdot \frac{v^{2}}{2 g}
$$

where $h_{f}$ is the head loss (m), $\lambda$ is the coefficient of frictional resistance [25-27], $l$ is the length of pipe (m), $v$ is the velocity of medium in the pipe $(\mathrm{m} / \mathrm{s})$, and $g$ is the gravitational acceleration $\left(\mathrm{m} / \mathrm{s}^{2}\right)$.

The specific frictional resistance $R$ refers to the resistance loss of pipe per meter, so we get formula (3) from formula (2):

$$
R=\frac{\lambda}{d} \cdot \frac{\rho v^{2}}{2}
$$

where $\rho$ is the density of medium $\left(\mathrm{kg} / \mathrm{m}^{3}\right)$ and $R$ is the specific frictional resistance $(\mathrm{Pa} / \mathrm{m})$.

Therefore, the specific frictional resistance, pipe diameter, and flow rate have the following relationship:

$$
R=0.81 \times \frac{\lambda G^{2}}{\rho d^{5}}
$$

where $G$ is the flow rate $(\mathrm{kg} / \mathrm{s})$.

For a heating network, the determination of the comprehensive specific frictional resistance needs to account for the change in flow rate during operation. However, the selection of the diameter through the flow rate and the specific frictional resistance still relates to the most unfavorable situation. Therefore, the flow rate $G$ in formula (4) is the design flow rate $G^{\prime}$. That is,

$$
d_{i}=0.959 \frac{\lambda^{1 / 5} G_{i}^{\prime(2 / 5)}}{\left(\rho R_{i}\right)^{1 / 5}},
$$

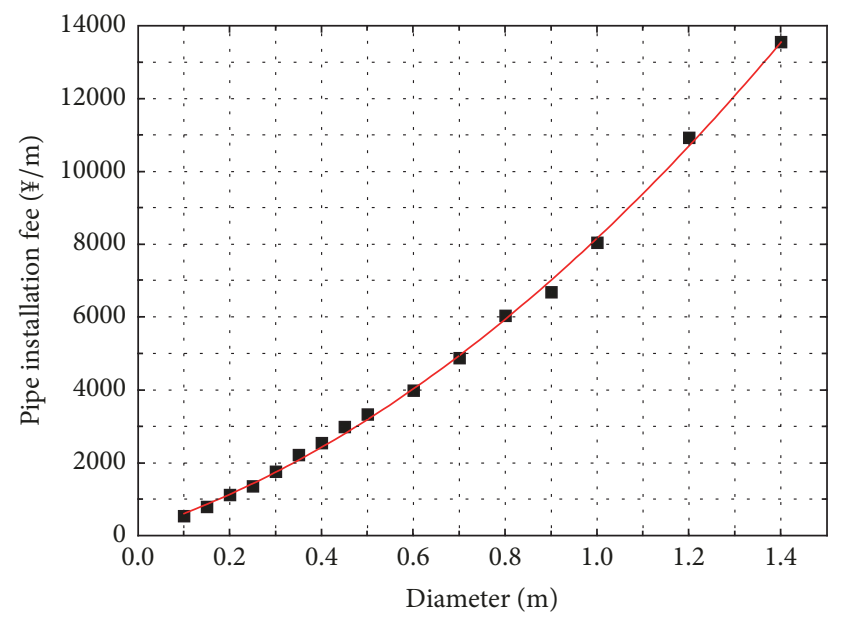

FIGURE 2: Fitting curve of heating pipe diameter and pipe installation fee.

where $d_{i}$ is the pipe diameter of pipe segment $i(\mathrm{~m}), G_{i}^{\prime}$ is the design flow rate of pipe segment $i(\mathrm{~kg} / \mathrm{s})$, and $R_{i}$ is the specific frictional resistance of pipe segment $i(\mathrm{~Pa} / \mathrm{m})$.

Applying the basic formula of specific heat capacity $Q=$ $c m \Delta t$ ( $c$ is the specific heat capacity, which for water is 4.2 $\times 10^{3} \mathrm{~J} /\left(\mathrm{kg} \cdot{ }^{\circ} \mathrm{C}\right), m$ is the quality $(\mathrm{kg}), \Delta t$ is the temperature difference $\left({ }^{\circ} \mathrm{C}\right)$, and $Q$ is the heat quantity $\left.(\mathrm{J})\right)$ to heating engineering, the following formula can be obtained:

$$
G=2.39 \times 10^{-4} \frac{Q}{\Delta t},
$$

where $Q$ is the thermal load (W), $\Delta t$ is the temperature difference $\left({ }^{\circ} \mathrm{C}\right)$, and $G$ is the flow rate of medium $(\mathrm{kg} / \mathrm{s})$.

Substituting formula (6) into formula (5), we get

$$
d_{i}=3.4133 \times 10^{-2} \Gamma_{i},
$$

where $\Gamma_{i}=\lambda^{1 / 5} Q_{i}^{\prime(2 / 5)} /\left(\rho R_{i}\right)^{1 / 5} \Delta t_{g h i}^{\prime}{ }^{2 / 5}, \Delta t_{g h i}^{\prime}$ is the design temperature difference between supply and return water of pipe segment $i\left({ }^{\circ} \mathrm{C}\right)$, and $Q_{i}^{\prime}$ is the design thermal load of pipe segment $i(\mathrm{w})$.

Substituting formula (7) into formula (1), the civil engineering cost of pipe segment $i$ can be given by

$$
\begin{aligned}
& M_{1 i} \\
& \quad=\left(1.1655 \times 10^{-3} a_{1} \Gamma_{i}^{2}+3.4133 \times 10^{-2} b_{1} \Gamma_{i}+c_{1}\right) l_{i},
\end{aligned}
$$

where $M_{1 i}$ is the civil engineering cost of pipe segment $i(¥)$ and $l_{i}$ is the length of pipe segment $i(\mathrm{~m})$.

2.2.2. The Pipe Installation Fee. The data from Chinese markets about pipe diameter $d$ and the corresponding pipe installation fee $m_{2}$ is shown in Figure 2.

The fitted curve is $m_{2}=3881.425 d^{2}+4134.162 d+$ 155.267 , whose $R$-squared value is as high as $99.73 \%$. Hence, the relationship between the pipe installation fee and the pipe 
diameter can also be expressed by a quadratic polynomial, as follows:

$$
m_{2}=a_{2} d^{2}+b_{2} d+c_{2}
$$

where $m_{2}$ is the installation fee of pipe with a diameter $d$ $(Y / \mathrm{m})$ and $a_{2}, b_{2}$, and $c_{2}$ are the fitting polynomial coefficients of the installation fee, which are determined by the specific situation.

Substituting formula (7) into formula (9), the installation fee of the pipe segment $i$ can be given by

$$
\begin{aligned}
& M_{2 i} \\
& \quad=\left(1.1655 \times 10^{-3} a_{2} \Gamma_{i}^{2}+3.4133 \times 10^{-2} b_{2} \Gamma_{i}+c_{2}\right) l_{i},
\end{aligned}
$$

where $M_{2 i}$ is the installation fee of the pipe segment $i(Y)$.

\subsubsection{The Electricity Fee}

(i) For a Heating System with Quality Regulation. A heating system with quality regulation is regulated simply by changing the water-supply temperature, so the flow rate of pipe segment $i$ is always the design flow rate $G_{i}^{\prime}$. Because the specific frictional resistance $R$ refers to the resistance loss of pipe per meter, the annual electricity consumption of pipe segment $i$ is

$$
W_{3}=R_{i} l_{i} \frac{G_{i}^{\prime}}{\rho} \tau_{i}
$$

where $W_{3}$ is the annual electricity consumption of pipe segment $i(\mathrm{~J})$ and $\tau_{i}$ is the run time of pipe segment $i$ per year (s).

So, the annual electricity fee for the pipe segment $i$ can be given by

$$
M_{3 i}=\frac{c_{3}}{\eta} W_{3}=\frac{c_{3}}{\eta \rho} R_{i} l_{i} G_{i}^{\prime} \tau_{i}
$$

where $M_{3 i}$ is the annual electricity fee for pipe segment $i$ ( $\left.¥\right)$, $c_{3}$ is the electrovalence $(¥ / \mathrm{J})$, and $\eta$ is the pump efficiency.

Substituting formula (6) into formula (12), we get

$$
M_{3 i}=2.39 \times 10^{-4} \frac{c_{3}}{\eta \rho \Delta t_{g h i}^{\prime}} R_{i} l_{i} Q_{i}^{\prime} \tau_{i} .
$$

(ii) For a Heating System with Flow Rate Regulation. A heating system with quality regulation is regulated by changing the flow rate. The large variation on the thermal load during the entire heating period results in a wide range of flow rate changes, so calculating the electricity fee according to the design flow rate $G_{i}^{\prime}$ does not adequately describe the actual situation. In order to estimate the electricity consumption accurately, we need to know the local thermal load changes and the corresponding hours to draw a thermal load duration diagram [28]. Under common conditions, the thermal load duration of the pipe segment $i$ in heating engineering can be described as Figure 3.

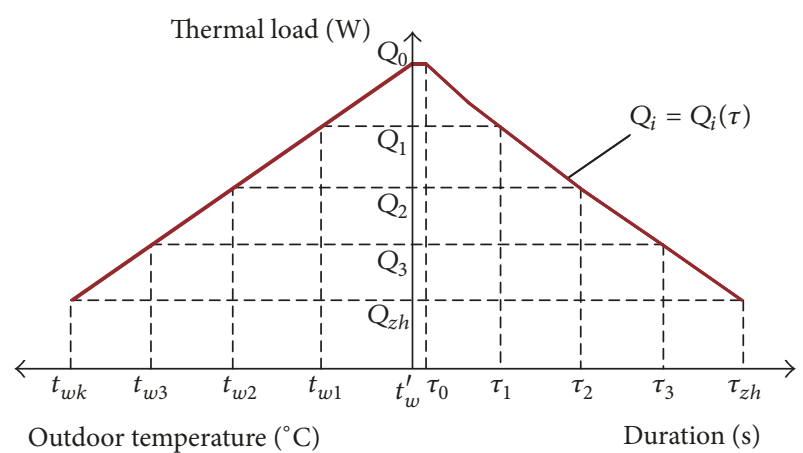

FIgURE 3: Thermal load duration diagram of the pipe segment $i$.

According to the definition of specific frictional resistance $R$, the annual electricity consumption of pipe segment $i$ is

$$
W_{3}=R_{i} l_{i} \frac{1}{\rho} \int_{\tau=0}^{\tau=\tau_{z h}} G_{i}(\tau) d \tau
$$

where $G_{i}$ is the actual flow rate of pipe segment $i(\mathrm{~kg} / \mathrm{s}), G_{i}(\tau)$ is the flow rate $(\mathrm{kg} / \mathrm{s})$-duration (s) function, and $\tau_{z h}$ is the duration corresponding to the minimum thermal load during a heating season (s).

The annual electricity fee for the pipe segment $i$ is

$$
M_{3 i}=\frac{c_{3}}{\eta} W_{3}=\frac{c_{3}}{\eta \rho} R_{i} l_{i} \int_{\tau=0}^{\tau=\tau_{z h}} G_{i}(\tau) d \tau .
$$

Substituting formula (6) into formula (15), the annual electricity fee for the pipe segment $i$ can be given by

$$
M_{3 i}=2.39 \times 10^{-4} \frac{c_{3}}{\eta \rho \Delta t_{g h i}^{\prime}} R_{i} l_{i} \Lambda_{i},
$$

where $\Lambda_{i}=\int_{\tau=\tau_{0}}^{\tau=\tau_{z h}} Q_{i}(\tau) d \tau, Q_{i}$ is the actual thermal load of pipe segment $i(\mathrm{w})$ and $Q_{i}(\tau)$ is the thermal load (w) duration (s) function, as shown in Figure 3.

2.2.4. The Fuel Cost. The fuel cost includes two parts: one is heat loss fuel cost; the other is thermal user fuel cost. Due to the irrelevance of the specific frictional resistance to thermal user fuel cost, there is no need to embody it in the mathematical model. However, massive, complicated pipeline networks increase heat loss along the route, so heat loss fuel cost should be included in the total cost rather than ignored. The heat loss fuel cost is different for different regulation modes, because it is associated with the medium temperature.

(i) For a Heating System with Flow Rate Regulation. The heat transfer coefficient $h$ refers to the amount of heat transfer per unit time per unit surface area for a $1^{\circ} \mathrm{C}$ temperature difference, so for a heating network adopting the flow rate regulation mode, the consumption of heat loss fuel is

$$
W_{4}=h\left(t_{k i}^{\prime}-t_{j}\right) \pi d_{i} l_{i} \tau_{i},
$$




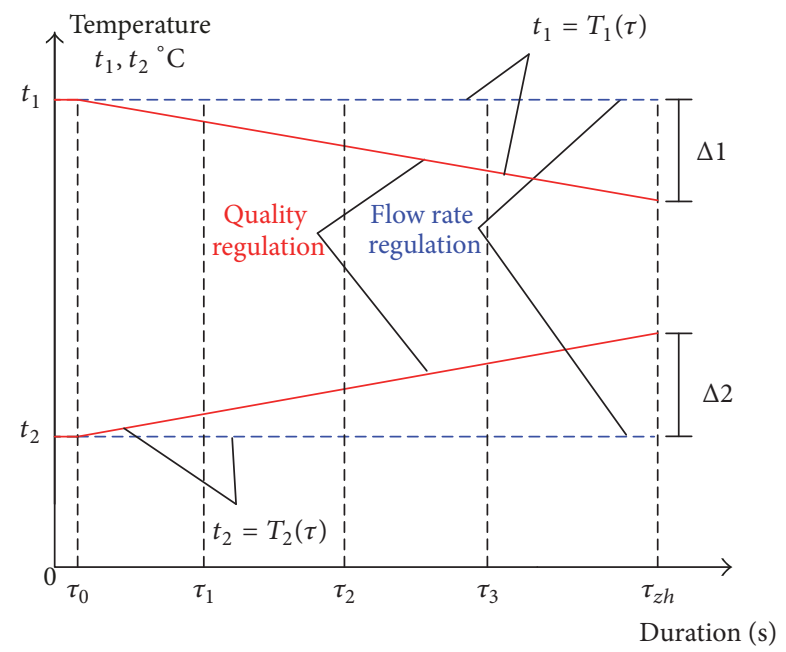

$t_{1}$-The temperature of supply water

$t_{2}$-The temperature of return water

FIGURE 4: Duration of actual water-supply or water-return temperature.

where $W_{4}$ is the consumption of heat loss fuel (J), $h$ is the heat transfer coefficient of the pipe surface $\left(\mathrm{w} / \mathrm{m}^{2} \cdot{ }^{\circ} \mathrm{C}\right), t_{j}$ is the ambient temperature of pipe segment $i\left({ }^{\circ} \mathrm{C}\right)$, and $t_{k i}^{\prime}$ is the design temperature of medium in pipe segment $i\left({ }^{\circ} \mathrm{C}\right)$. For the water-supply pipe, $k=1, t_{k i}^{\prime}=t_{g i}^{\prime}=t_{h i}^{\prime}+\Delta t_{g h i}^{\prime}$ and for the water-return pipe, $k=2, t_{k i}^{\prime}=t_{h i}^{\prime}$, where $t_{g i}^{\prime}$ is the design water-supply temperature of pipe segment $i\left({ }^{\circ} \mathrm{C}\right), t_{h i}^{\prime}$ is the design water-return temperature of pipe segment $i\left({ }^{\circ} \mathrm{C}\right)$.

So the annual heat loss fuel cost is

$$
M_{4 i}=W_{4} \cdot c_{4}=c_{4} h\left(t_{k i}^{\prime}-t_{j}\right) \pi d_{i} l_{i} \tau_{i},
$$

where $M_{4 i}$ is the annual heat loss fuel cost of the pipe segment $i(¥)$ and $c_{4}$ is the fuel price ( $\left.¥ / \mathrm{J}\right)$.

Substituting formula (7) into formula (18), the annual heat loss fuel cost of the pipe segment $i$ can be given by

$$
M_{4 i}=3.4133 \times 10^{-2} c_{4} h\left(t_{k i}^{\prime}-t_{j}\right) \pi \tau_{i} l_{i} \Gamma_{i} .
$$

(ii) For a Heating System with Quality Regulation. For heatsupply networks adopting the quality regulation mode, calculating the heat loss fuel cost by the design temperature is unreasonable due to the variance of the medium temperature in the pipe. As we know, compared with the design watersupply temperature and design water-return temperature, a reduction in actual water-supply temperature of $\Delta 1$ is equal to an increase of $\Delta 2$ of the actual water-return temperature in the quality regulation networks [8]. This is described in Figure 4.

So, the following formula can be given:

$$
t_{k i}=t_{h i}^{\prime}+\frac{\Delta t_{g h i}^{\prime}}{2}-(-1)^{k} \frac{\Delta t_{g h i}}{2},
$$

where $t_{k i}$ is the actual temperature of medium in pipe segment $i\left({ }^{\circ} \mathrm{C}\right)$ and $\Delta t_{g h i}$ is the actual temperature difference between supply and return water of pipe segment $i\left({ }^{\circ} \mathrm{C}\right)$, as shown in Figure 4.

According to the definition of heat transfer coefficient $h$, the consumption of heat loss fuel is

$$
W_{4}=h \pi d_{i} l_{i} \int_{\tau=0}^{\tau=\tau_{z h}}\left(t_{k i}-t_{j}\right) d \tau
$$

Substituting formula (20) into formula (21), we get the consumption of heat loss fuel:

$$
\begin{aligned}
W_{4} & =h \pi d_{i} l_{i}\left[\left(t_{h i}^{\prime}+\frac{\Delta t_{g h i}^{\prime}}{2}-t_{j}\right) \cdot \tau_{z h}\right. \\
& \left.-\frac{(-1)^{k}}{2} \int_{\tau=0}^{\tau=\tau_{z h}} \Delta t_{g h i} d \tau\right] .
\end{aligned}
$$

So, the annual heat loss fuel cost of the pipe segment $i$ is

$$
\begin{gathered}
M_{4 i}=c_{4} W_{4}=c_{4} h \pi d_{i} l_{i}\left[\left(t_{h i}^{\prime}+\frac{\Delta t_{g h i}^{\prime}}{2}-t_{j}\right) \cdot \tau_{z h}\right. \\
\left.-\frac{(-1)^{k}}{2} \int_{\tau=0}^{\tau=\tau_{z h}} \Delta t_{g h i} d \tau\right] .
\end{gathered}
$$

Substituting formula (7) into formula (23), the annual heat loss fuel cost of the pipe segment $i$ can be given by

$$
\begin{gathered}
M_{4 i}=3.4133 \times 10^{-2} c_{4} h \pi l_{i} \Gamma_{i}\left[\left(t_{h i}^{\prime}+\frac{\Delta t_{g h i}^{\prime}}{2}-t_{j}\right) \tau_{z h}\right. \\
\left.-\frac{(-1)^{k}}{2} \int_{\tau=0}^{\tau=\tau_{z h}} \Delta t_{g h i} d \tau\right] .
\end{gathered}
$$

For a heating system with quality regulation, the actual flow rate $G_{i}$ is always the design flow rate $G_{i}^{\prime}$, so we know

$$
\frac{Q_{i}}{\Delta t_{g h i}}=\frac{Q_{i}^{\prime}}{\Delta t_{g h i}^{\prime}} .
$$

Substituting formula (25) into formula (24), we get

$$
\begin{aligned}
M_{4 i} & =3.4133 \times 10^{-2} c_{4} h \pi l_{i} \Gamma_{i}\left[\left(t_{h i}^{\prime}+\frac{\Delta t_{g h i}^{\prime}}{2}-t_{j}\right) \tau_{z h}\right. \\
& \left.-\frac{(-1)^{k} \Delta t_{g h i}^{\prime}}{2 Q_{i}^{\prime}} \Lambda_{i}\right] .
\end{aligned}
$$

2.2.5. The Objective Function. For pipe segment $i$, the objective function is the Present Value Cost in its lifespan of $n$ years. Supposing the discount rate is $\varepsilon$, it can be described as follows. 


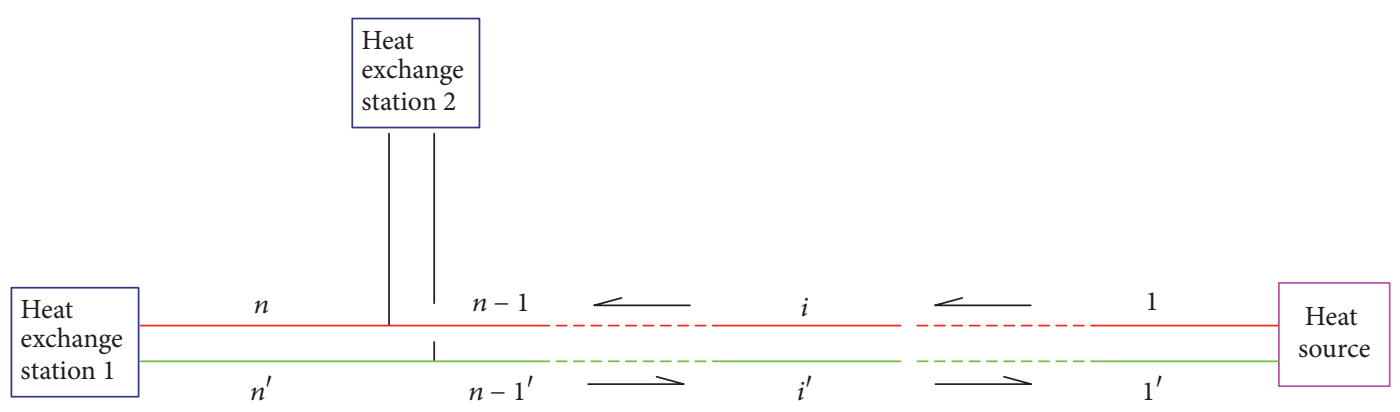

FIGURE 5: A branched network diagram.

(i) For a Heating System with Quality Regulation

$$
\begin{aligned}
\mathrm{PC} & =M_{1 i}+M_{2 i}+\left(M_{3 i}+M_{4 i}\right) \cdot\left(\frac{P}{A} \cdot \varepsilon \cdot n\right) \\
& =\left(1.1655 \times 10^{-3} a \Gamma_{i}^{2}+3.4133 \times 10^{-2} b \Gamma_{i}+c\right) l_{i} \\
& +\left[2.39 \times 10^{-4} \frac{c_{3}}{\eta \rho \Delta t_{g h i}^{\prime}} R_{i} l_{i} Q_{i}^{\prime} \tau_{i}+3.4133\right. \\
& \times 10^{-2} c_{4} h \pi l_{i} \Gamma_{i}\left(\left(t_{h i}^{\prime}+\frac{\Delta t_{g h i}^{\prime}}{2}-t_{j}\right) \tau_{z h}\right. \\
& \left.\left.-\frac{(-1)^{k} \Delta t_{g h i}^{\prime}}{2 Q_{i}^{\prime}} \Lambda_{i}\right)\right] \times\left(\frac{P}{A} \cdot \varepsilon \cdot n\right)
\end{aligned}
$$

(ii) For a Heating System with Flow Rate Regulation

$$
\begin{aligned}
\mathrm{PC} & =M_{1 i}+M_{2 i}+\left(M_{3 i}+M_{4 i}\right) \cdot\left(\frac{P}{A} \cdot \varepsilon \cdot n\right) \\
& =\left(1.1655 \times 10^{-3} a \Gamma_{i}^{2}+3.4133 \times 10^{-2} b \Gamma_{i}+c\right) l_{i} \\
& +\left(2.39 \times 10^{-4} \times \frac{c_{3}}{\eta \rho \Delta t_{g h i}^{\prime}} R_{i} l_{i} \Lambda_{i}+3.4133\right. \\
& \left.\times 10^{-2} c_{4} h\left(t_{k i}^{\prime}-t_{j}\right) \pi \tau_{i} l_{i} \Gamma_{i}\right) \times\left(\frac{P}{A} \cdot \varepsilon \cdot n\right),
\end{aligned}
$$

where PC is the Present Value Cost $(¥), \varepsilon$ is the discount rate, and $n$ is the life period (years), $a=a_{1}+a_{2}, b=b_{1}+b_{2}, c=c_{1}+c_{2}$, $(P / A \cdot \varepsilon \cdot n)=\left((1+\varepsilon)^{n}-1\right) / \varepsilon(1+\varepsilon)^{n}$.

\subsection{Establishment of the Constraint Conditions}

2.3.1. The Constraint Conditions of Medium Pressure. The pressure in the pipe must meet certain requirements in order to ensure normal operation of the system and prevent pipe burst or medium vaporization. As the research object is the primary network system, the lower pressure limit must guarantee that high-temperature water does not vaporize in the pipeline, while the upper limit is the pressure that the pipe and pipe fittings can bear. Additionally, the waterreturn temperature is generally less than $100^{\circ} \mathrm{C}$, and for any water-supply pipe segment $i$, there must be a corresponding water-return pipe segment $i^{\prime}$ whose pressure is lower than the pressure in the pipe segment $i$. Therefore, only the water-supply pipes need to obey the pressure constraints. In addition, in order to ensure that the pressure in the pipe segment meets the requirements, the starting and ending points of the pipe must also meet the requirements.

A branched network diagram without distributed pressure pumps is shown in Figure 5. Pipe segments $1^{\prime}, 2^{\prime}, 3^{\prime}, \ldots$, $n^{\prime}, n, n-1, n-2, \ldots, 3,2,1$ constitute the trunk line. Under normal circumstances, the constant pressure point is located at the entrance of the circulating pumps, that is, the end of pipe segment $1^{\prime}$. Assuming that the pressure at the constant pressure point is $P_{1^{\prime} m o}$, the pressure at any section of any pipe segment can be calculated.

According to the Bernoulli equation (Bernoulli's principle), the pressure at the start of pipe segment $i$ can be given by

$$
\begin{aligned}
P_{i s h i}= & P_{1^{\prime} m o}+\left(Z_{1^{\prime} m o}-Z_{i s h i}\right) \gamma+\frac{\rho v_{1^{\prime}}^{2}}{2}-\frac{\rho v_{i}^{2}}{2} \\
& +(1+\alpha)\left(\sum_{f=1^{\prime}}^{i+1} R_{f} l_{f}+R_{i} l_{i}\right)+\Delta P_{\text {zhan }} .
\end{aligned}
$$

So the pressure constraint condition of pipe segment $i$ can be given by

$$
\begin{aligned}
P_{\text {tgi' } i^{\prime} \text { ihua }} \leq & P_{1^{\prime} m o}+\left(Z_{1^{\prime} m o}-Z_{i s h i}\right) \gamma+\frac{\rho v_{1^{\prime}}^{2}}{2}-\frac{\rho v_{i}^{2}}{2} \\
& +(1+\alpha)\left(\sum_{f=1^{\prime}}^{i+1} R_{f} l_{f}+R_{i} l_{i}\right)+\Delta P_{\text {zhan }} \\
\leq & P_{\text {cheng }},
\end{aligned}
$$

where $P_{i s h i}$ is the pressure at the start of pipe segment $i(\mathrm{~Pa})$, $v_{i}$ is the flow velocity of the medium in pipe segment $i(\mathrm{~m} / \mathrm{s})$, $Z_{i s h i}$ is the topographic height at the start of pipe segment $i$ (m), $P_{1^{\prime} m o}$ is the pressure at the end of pipe segment $1^{\prime}$ (the constant pressure point) $(\mathrm{Pa}), v_{1^{\prime}}$ is the flow velocity of the medium in pipe segment $1^{\prime}(\mathrm{m} / \mathrm{s}), Z_{1^{\prime} m o}$ is the topographic height at the end of pipe segment $1^{\prime}(\mathrm{m}), \Delta P_{\mathrm{zhan}}$ is the resistance loss at heat exchange station $(\mathrm{Pa}), \alpha$ is the ratio of 
the local resistance to the resistance along the path, $P_{t g i}{ }^{\text {qihua }}$ is the saturation steam pressure corresponding to the design water-supply temperature $t_{g i}^{\prime}(\mathrm{Pa}), P_{\text {cheng }}$ is the maximum pressure that the pipe and pipe fittings can bear $(\mathrm{Pa})$, and $\gamma$ is the volumetric weight $\left(\mathrm{N} / \mathrm{m}^{3}\right), \gamma=\rho g$.

In order to simplify formula (30), the item $\left(\rho v_{1^{\prime}}^{2} / 2-\rho v_{i}^{2} / 2\right)$ can be moved as follows:

$$
\begin{aligned}
& P_{\text {tgi } i^{\prime} \text { qihua }}-\left(\frac{\rho v_{1^{\prime}}^{2}}{2}-\frac{\rho v_{i}^{2}}{2}\right) \\
& \leq P_{1^{\prime} m o}+\left(Z_{1^{\prime} m o}-Z_{i s h i}\right) \gamma \\
& +(1+\alpha)\left(\sum_{f=1^{\prime}}^{i+1} R_{f} l_{f}+R_{i} l_{i}\right)+\Delta P_{\text {zhan }} \\
& \leq P_{\text {cheng }}-\left(\frac{\rho v_{1^{\prime}}^{2}}{2}-\frac{\rho v_{i}^{2}}{2}\right) .
\end{aligned}
$$

There is little difference among different pipelines in terms of flow velocity, for which the range is $0 \sim 4 \mathrm{~m} / \mathrm{s}$ [ 29 , 30]; that is, the value of $\left(\rho v_{1^{\prime}}^{2} / 2-\rho v_{i}^{2} / 2\right)$ is $-8000 \sim 8000 \mathrm{~Pa}$. Compared with $P_{\text {tgi' }}$ ihua and $P_{\text {cheng, }}$, its order of magnitude is low. Therefore, formula (31) can be simplified to the following form:

$$
\begin{aligned}
P_{\text {tgi' } \text { qihua }}+8000 \leq & P_{1^{\prime} \text { mo }}+\left(Z_{1^{\prime} m o}-Z_{i s h i}\right) \gamma \\
& +(1+\alpha)\left(\sum_{f=1^{\prime}}^{i+1} R_{f} l_{f}+R_{i} l_{i}\right) \\
& +\Delta P_{\text {zhan }} \leq P_{\text {cheng }}-8000 .
\end{aligned}
$$

In this way, not only has the formula been simplified, but also a certain margin has been set for the upper and lower limits.

From the Antoine equation [31], we know that $P_{\text {tgi }}$ qihua $=$ $e^{9.3876-3826.36 /\left(\operatorname{tg}^{\prime}+227.68\right)} \times 10^{6} \mathrm{~Pa}$, so the pressure constraint condition at the start of pipe segment $i$ can be given by

$$
\begin{aligned}
e^{\Theta_{i}} \times 10^{6}+8000 \leq & P_{1^{\prime} m o}+\left(Z_{1^{\prime} m o}-Z_{i s h i}\right) \gamma \\
& +(1+\alpha)\left(\sum_{f=1^{\prime}}^{i+1} R_{f} l_{f}+R_{i} l_{i}\right)
\end{aligned}
$$

$$
+\Delta P_{\text {zhan }} \leq P_{\text {cheng }}-8000,
$$

where $\Theta_{i}=9.3876-3826.36 /\left(t_{h i}^{\prime}+\Delta t_{g h i}^{\prime}+227.68\right)$.

As described above, the pressure at the end of pipe segment $i$ is equal to the pressure at the start of pipe segment $i+1$ because the velocity difference has been set as a margin for the upper and lower limits, which means the pressure constraint at the end of pipe segment $i$ has been validated in the previous step by the pressure constraint of pipe segment $i+1$. Therefore, the pressure constraint at the end of pipe segment $i$ can be ignored.

2.3.2. The Constraint Condition of Design Temperature Difference between Supply and Return Water. The design temperature difference between supply and return water $\Delta t_{g h i}^{\prime}$ should be limited to a certain range. Too small a temperature difference can result in reduced and inadequate heat exchange, while too large a temperature difference may need a very high water-supply temperature, which may be difficult to achieve or may incur a very high cost in practice. Therefore, the design temperature difference between supply and return water should be limited by

$$
\Delta t_{g h \min }^{\prime} \leq \Delta t_{g h i}^{\prime} \leq \Delta t_{g h \max }^{\prime}
$$

2.3.3. The Constraint Condition of the Flow Velocity. The flow velocity in the pipes should be restricted to a certain range, as follows:

$$
v_{\min } \leq v_{i}=\frac{4 G_{i}^{\prime}}{\rho \pi d_{i}^{2}} \leq v_{\max } .
$$

Substituting formulas (6) and (7) into formula (35), the constraint conditions of the flow velocity can be given by

$$
v_{\min } \leq 0.821 \frac{Q_{i}^{\prime}}{\rho \pi \Delta t_{g h i}^{\prime} \Gamma_{i}^{2}} \leq v_{\max } .
$$

2.4. Establishment of a Mathematical Model. Based on the above analysis, a mathematical model of Present Value Cost to determine the comprehensive specific frictional resistance of pipe segment $i$ can be given as follows.

(i) For a Heating System with Quality Regulation

$$
\begin{aligned}
\min \mathrm{PC} & =M_{1 i}+M_{2 i}+\left(M_{3 i}+M_{4 i}\right) \cdot\left(\frac{P}{A} \cdot \varepsilon \cdot n\right) \\
= & \left(1.1655 \times 10^{-3} a \Gamma_{i}^{2}+3.4133 \times 10^{-2} b \Gamma_{i}+c\right) l_{i} \\
+ & {\left[2.39 \times 10^{-4} \frac{c_{3}}{\eta \rho \Delta t_{g h i}^{\prime}} R_{i} l_{i} Q_{i}^{\prime} \tau_{i}+3.4133 \times 10^{-2} c_{4} h \pi l_{i} \Gamma_{i}\left(\left(t_{h i}^{\prime}+\frac{\Delta t_{g h i}^{\prime}}{2}-t_{j}\right) \tau_{z h}-\frac{(-1)^{k} \Delta t_{g h i}^{\prime}}{2 Q_{i}^{\prime}} \Lambda_{i}\right)\right] } \\
& \times\left(\frac{P}{A} \cdot \varepsilon \cdot n\right) .
\end{aligned}
$$


(ii) For a Heating System with Flow Rate Regulation

$$
\begin{aligned}
& \min \quad \mathrm{PC}=M_{1 i}+M_{2 i}+\left(M_{3 i}+M_{4 i}\right) \cdot\left(\frac{P}{A} \cdot \varepsilon \cdot n\right) \\
&=\left(1.1655 \times 10^{-3} a \Gamma_{i}^{2}+3.4133 \times 10^{-2} b \Gamma_{i}+c\right) l_{i} \\
&+\left(2.39 \times 10^{-4} \times \frac{c_{3}}{\eta \rho \Delta t_{g h i}^{\prime}} R_{i} l_{i} \Lambda_{i}+3.4133 \times 10^{-2} c_{4} h\left(t_{k i}^{\prime}-t_{j}\right) \pi \tau_{i} l_{i} \Gamma_{i}\right) \times\left(\frac{P}{A} \cdot \varepsilon \cdot n\right) \\
& \text { St } \quad \Delta t_{g h \min }^{\prime} \leq \Delta t_{g h i}^{\prime} \leq \Delta t_{g h \max }^{\prime} Q_{i}^{\prime} \\
& v_{\min } \leq 0.821 \frac{\rho \pi \Delta t_{g h i}^{\prime} \Gamma_{i}^{2}}{\rho v_{\max }} \\
& e^{\Theta_{i}} \times 10^{6}+8000 \leq P_{1^{\prime} m o}+\left(Z_{1^{\prime} m o}-Z_{i s h i}\right) \gamma+(1+\alpha)\left(\sum_{f=1^{\prime}}^{i+1} R_{f} l_{f}+R_{i} l_{i}\right)+\Delta P_{\text {zhan }} \leq P_{\text {cheng }}-8000
\end{aligned}
$$

For the water-supply pipes, the constraint conditions are the inequalities (39), (40), and (41), while, for the water-return pipes, the constraint conditions are the inequalities (39) and (40).

2.5. The Solvability Analysis of the Mathematical Model. The objective function $\operatorname{PC}\left(R_{i}, \Delta t_{g h i}^{\prime}\right)$ we established is a continuous real valued function map, and the value ranges of the decision variable $R_{i}$ and $\Delta t_{\text {ghi }}^{\prime}$ are compact sets. Therefore, we can know by the Weierstrass Theorem [32] that there must be a solution vector $\left(R_{i}, \Delta t_{g h i}^{\prime}\right)$ that makes the objective function a minimum.

2.6. The Analysis of Algorithm. The mathematical model established above belongs to the two-dimensional extreme value problem under inequality constraints. The Complex method is selected as the optimization algorithm and is used to solve the models, whose function is to solve the $n$-dimensional extremum problem under the equality and inequality constraints.

2.7. The Value of Comprehensive Specific Frictional Resistance. According to the actual engineering, the basic parameters in the objective function and the constraint conditions can be determined, while the total heat load of the heat consumers that the pipe segment $i$ provides heat for during the heating period $\Lambda_{i}=\int_{\tau=\tau_{0}}^{\tau=\tau_{z h}} Q_{i}(\tau) d \tau$ can be calculated. Substitute all of them into the mathematical models (37) (41) and solve the mathematical model. We can obtain the comprehensive specific frictional resistance of the pipe segment $i R_{i}$ and the design temperature difference between supply and return water $\Delta t_{g h i}^{\prime}$.

\section{Application}

3.1. Case. We have planned the heating engineering for Yangyuan County in China. The heating system is based on flow rate regulation as the main regulation mode, considering its energy-saving advantage. In the planning process of the network, the two schemes, comprehensive specific frictional resistance and economic specific frictional resistance, are used to optimize the pipe diameters.

According to market research, the calculation parameters have been selected as follows.

Coefficient of frictional resistance $\lambda=0.0196$, discount rate $\varepsilon=7 \%$, electrovalence $c_{3}=2.0278 \times 10^{-7} ¥ / \mathrm{J}$, fuel price $c_{4}=1.7088175 \times 10^{-8} ¥ / \mathrm{J}$, the lifespan $n=20$ years, run time per year $\tau_{i}=14515200 \mathrm{~s}$ (equivalent to 168 days), pump efficiency $\eta=70 \%$, ambient temperature of pipe segments $t_{j}=0^{\circ} \mathrm{C}$, heat transfer coefficient of pipe surface $h=1.22 \mathrm{w} /\left(\mathrm{m}^{2} .^{\circ} \mathrm{C}\right)$, design water-return temperature $t_{h i}^{\prime}=70^{\circ} \mathrm{C}$, fitting polynomial coefficients of civil engineering cost $a_{1}=255.67292, b_{1}=$ 498.81903, and $c_{1}=113.13293$, fitting polynomial coefficients of pipe installation fee $a_{2}=3881.42532, b_{2}=4134.16167$, and $c_{2}=155.26657$, the ratio of local resistance to resistance along the path $\alpha=0.3$, the resistance loss at heat exchange station $\Delta P_{\text {zhan }}=0.1 \mathrm{MPa}, P_{1^{\prime} m o}=0.1 \mathrm{MPa}$, upper bound of flow velocity $v_{\max }=3.5 \mathrm{~m} / \mathrm{s}$, lower bound of flow velocity $v_{\text {min }}=0.5 \mathrm{~m} / \mathrm{s}$, upper bound of design temperature difference between supply and return water $\Delta t_{\text {ghmin }}^{\prime}=30^{\circ} \mathrm{C}$, lower bound of design temperature difference between supply and return water $\Delta t_{g h \max }^{\prime}=60^{\circ} \mathrm{C}$, upper bound of pressure $P_{\text {cheng }}=1.6 \mathrm{MPa}, \rho=1000 \mathrm{~kg} / \mathrm{m}^{3}$, and $\gamma=9807 \mathrm{~N} / \mathrm{m}^{3}$, and the duration of outdoor temperature in Zhangjiakou are shown in Table 1.

According to the site investigations, and to follow the trends of the existing pipeline network, the whole heating area was divided into three independent heating areas as shown in Figure 6: the planning floor area of heating area A is $9.61 \times 10^{6} \mathrm{~m}^{2}$, the planning floor area of heating area $B$ is 6.57 $\times 10^{6} \mathrm{~m}^{2}$, and the planning floor area of heating area $\mathrm{C}$ is 4.75 $\times 10^{6} \mathrm{~m}^{2}$. 


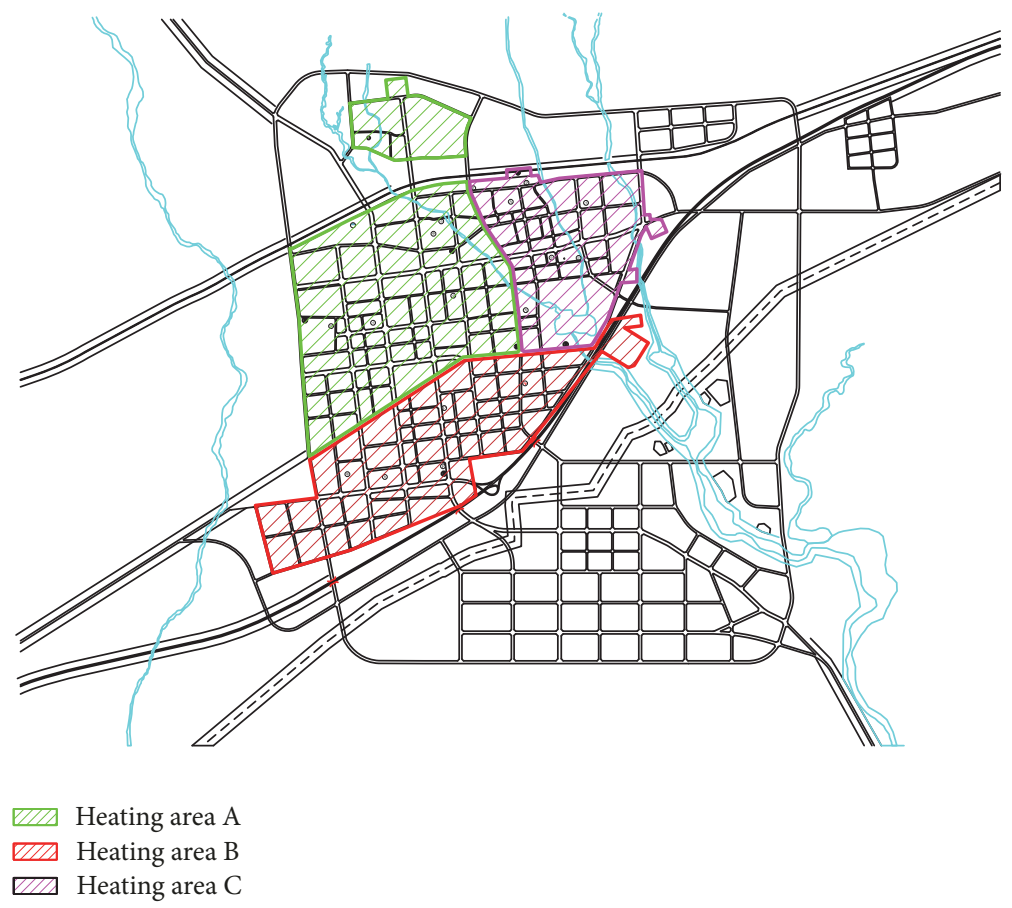

FIgURE 6: The map of heating areas A, B, and C.

TABLE 1: Duration of outdoor temperature in Zhangjiakou.

\begin{tabular}{|c|c|c|}
\hline Number & $\begin{array}{c}\text { Outdoor } \\
\text { temperature } \\
\left({ }^{\circ} \mathrm{C}\right) \\
\end{array}$ & $\begin{array}{l}\text { Duration of outdoor } \\
\text { temperature (hours) }\end{array}$ \\
\hline (1) & $>5$ & 4728 \\
\hline (2) & 5 & 4032 \\
\hline (3) & 4 & 3850 \\
\hline (4) & 3 & 3667 \\
\hline (5) & 2 & 3483 \\
\hline (6) & 1 & 3299 \\
\hline (7) & 0 & 3114 \\
\hline (8) & -1 & 2927 \\
\hline (9) & -2 & 2740 \\
\hline (10) & -3 & 2552 \\
\hline (11) & -4 & 2363 \\
\hline (12) & -5 & 2173 \\
\hline (13) & -6 & 1981 \\
\hline (14) & -7 & 1788 \\
\hline (15) & -8 & 1593 \\
\hline (16) & -9 & 1397 \\
\hline (17) & -10 & 1197 \\
\hline (18) & -11 & 996 \\
\hline (19) & -12 & 790 \\
\hline (20) & -13 & 579 \\
\hline (21) & -14 & 361 \\
\hline (22) & -15 & 120 \\
\hline
\end{tabular}

In this study, we take heating area $\mathrm{C}$ as an example. In Figure 7, only water-supply pipes are marked, while the position and trend of water-return pipes are in agreement with the corresponding water-supply pipes. In the following description, the numbers with "' "represent the water-return pipes, while the numbers without “'” represent the watersupply pipes.

The entire calculation process is as follows:

(1) Choose the most distant loop from the heat source (the trunk line), that is, $100 \rightarrow 101 \rightarrow 102 \rightarrow 103 \rightarrow 104 \rightarrow$ $105 \rightarrow 106 \rightarrow 107 \rightarrow 107^{\prime} \rightarrow 106^{\prime} \rightarrow 105^{\prime} \rightarrow 104^{\prime} \rightarrow$ $103^{\prime} \rightarrow 102^{\prime} \rightarrow 101^{\prime} \rightarrow 100^{\prime}$

(2) Calculate the $R_{i}$ and $\Delta t_{g h i}^{\prime}$ of the water-return pipes in the most distant loop with the models (38), (39), and (40);

(3) Follow the order $107 \rightarrow 106 \rightarrow 105 \rightarrow 104 \rightarrow 103 \rightarrow$ $102 \rightarrow 101 \rightarrow 100$ to calculate the $R_{i}$ and $\Delta t_{\text {ghi }}^{\prime}$ of the watersupply pipes in the most distant loop with the models (38), (39), (40), and (41);

(4) For the other branch loops, calculate the $R_{i}$ and $\Delta t_{g h i}^{\prime}$ of the water-return pipes that have not been calculated with the models (38), (39), and (40), and then calculate the $R_{i}$ and $\Delta t_{g h i}^{\prime}$ of the water-supply pipes that have not been calculated, following the order from far to near with the models (38), (39), (40), and (41).

The calculation results are shown in Table 2. As expected, the range of values for traditional economic specific frictional resistance is $30 \sim 70 \mathrm{~Pa} / \mathrm{m}$.

The optimization results in Table 2 show that the design water-supply temperature for pipe segment 107 is $120^{\circ} \mathrm{C}$, which is different from all the others. The reasons for this 


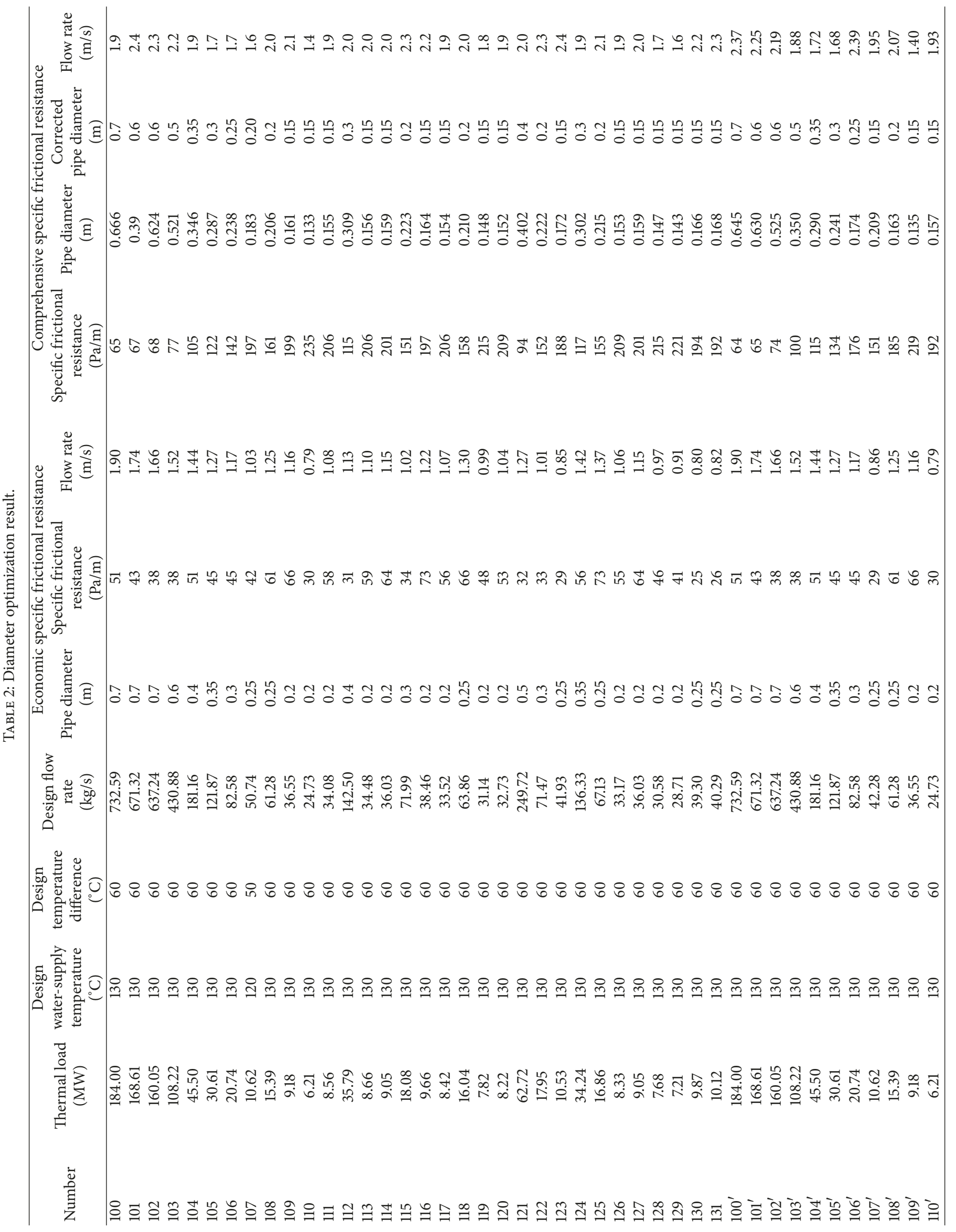




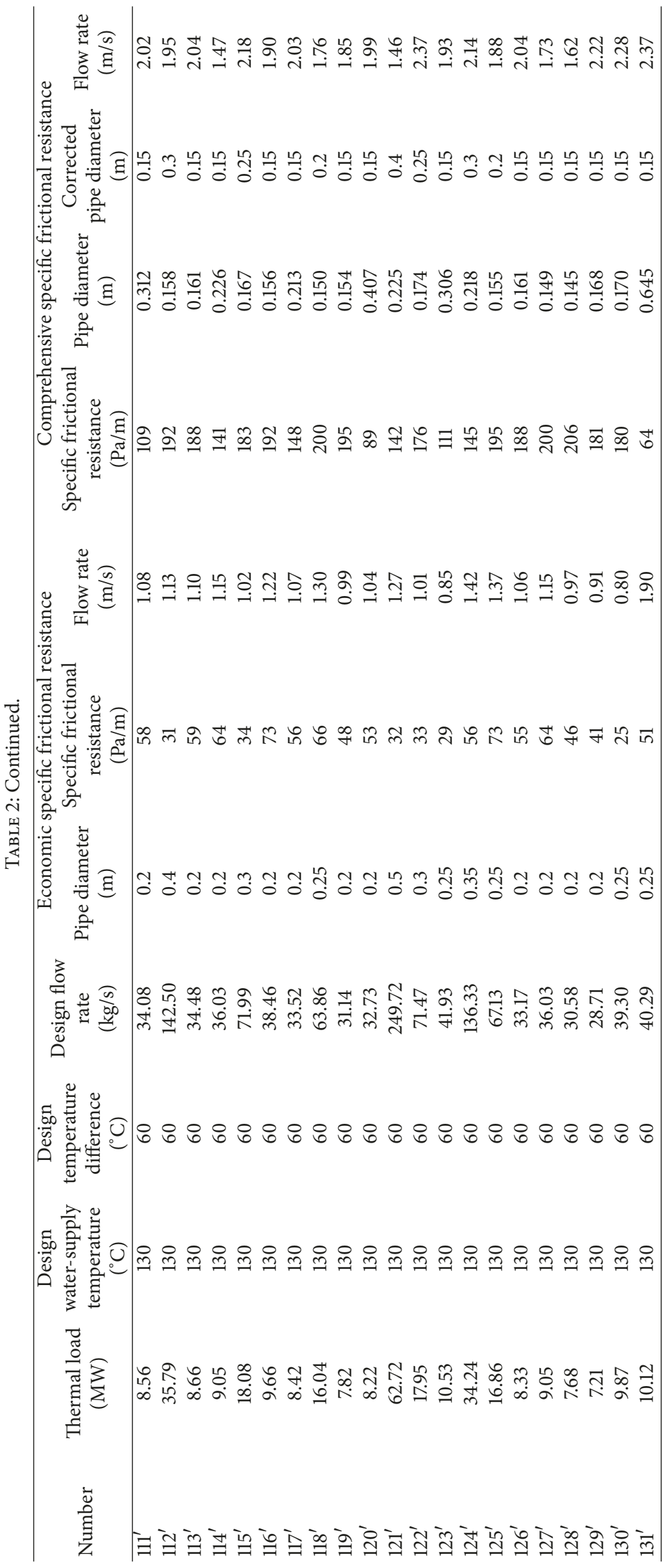




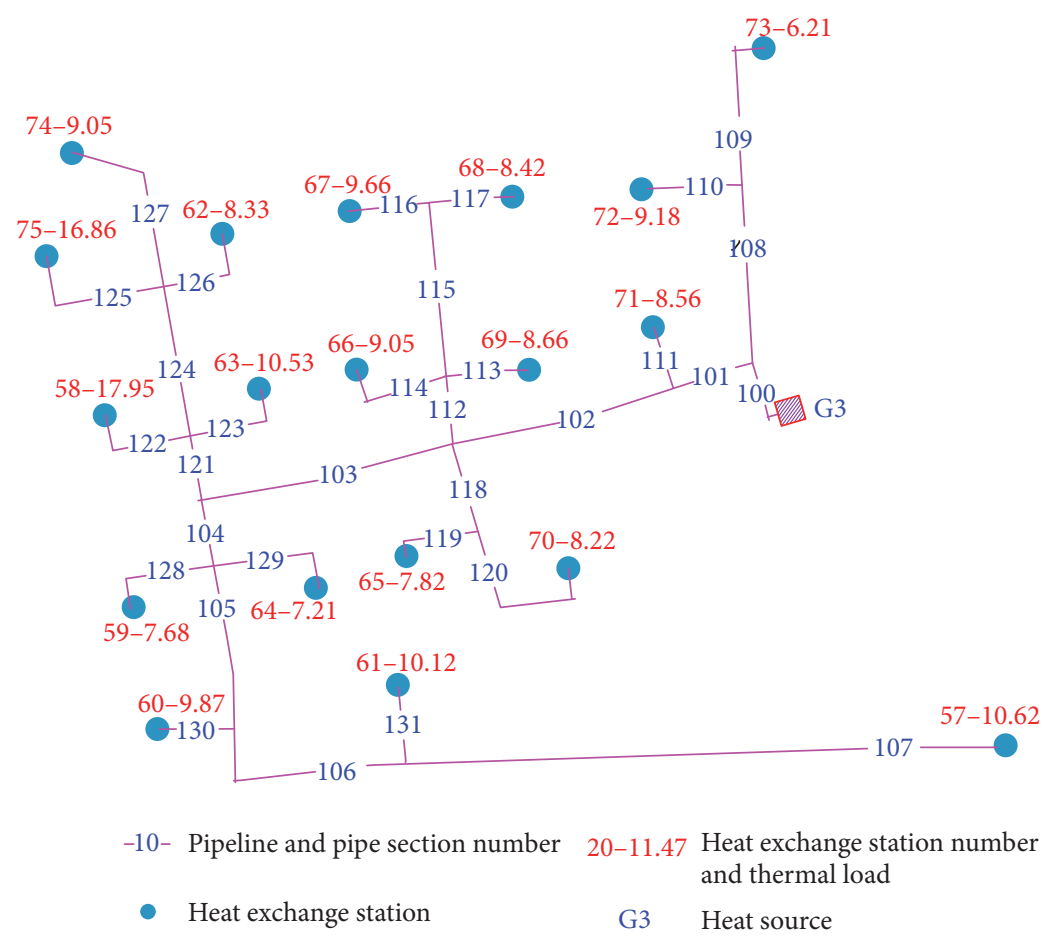

Figure 7: Heating network in heating area C.

are the long distance from the heat source to the pipe and the high elevation of the pipe, which lead to a lot of pressure reduction in the pipe segment. Therefore, the only way to ensure the pipe pressure is higher than the vaporization pressure is to decrease the water-supply temperature. If the pressure constraint formula (41) is removed, the result for pipe segment 107 will be $R_{107}=188, \Delta t_{g 107}^{\prime}=130^{\circ} \mathrm{C}$, at which temperature the medium will vaporize. Because there must be one water-supply temperature for the entire engineering, so this optimization result is not desirable. There are two solutions to this problem: (1) the entire heating system is recalculated according to a lower water-supply temperature in all the results until the optimization results $\Delta t_{g i}^{\prime}$ of all the segments are same; (2) the heat consumers after the pipe segments whose optimization results of water-supply temperature are different from the others take the indirect connection form. In this case, taking into account the fact that only one segment pipe is different from the others, it is obvious that the second solution is more reasonable. That is, pipe segment 107 and the heat user 57 should connect with the trunk line indirectly.

From the perspective of the entire engineering application, based on the calculation of the various costs and incomes, including heat source construction fee, heat exchange station construction fee, primary network construction fee, electricity fee, heat loss fuel cost, thermal user fuel cost, water fee, maintenance cost, labor wage, heating charges, and residual value of fixed assets, the economic effect evaluation indexes of the two schemes are shown in Table 3.

By comparison, we can see that under the premise of ensuring the same heating quality, the economic effect evaluation indexes of scheme one are better. Compared to scheme two, the Payback Period is lowered, the Initial Investment is reduced by $5 \%$, the Present Value Cost is decreased by $¥ 23.6039$ million, the Net Present Value has an increase of $¥ 34.1176$ million, the Rate of Return on Investment is increased by $4.98 \%$, and the Internal Rate of Return is increased by $0.6 \%$, which demonstrate the feasibility and superiority of the comprehensive specific frictional resistance.

3.2. Discussion. Through the analysis of the case and the mathematical models, we show there are many factors that influence the value of comprehensive specific frictional resistance, including the coefficient of frictional resistance $\lambda$, heat transfer coefficient of pipe surface $h$, electrovalence $c_{3}$, fuel price $c_{4}$, discount rate $\varepsilon$, lifespan $n$, pump efficiency $\eta$, and primary network construction fee. The various values of the above parameters in different engineering applications will lead to the different values of comprehensive specific frictional resistance. In addition, the comprehensive specific frictional resistance has different sensitivities for different parameters.

Using the calculation parameters in Section 3.1, and setting the design water-supply temperature $\Delta t_{g}^{\prime}=130^{\circ} \mathrm{C}$, we get the sensitivities as shown in Figure 8.

Similarly, using the calculation parameters in Section 3.1, and setting the design water-supply temperature $\Delta t_{g}^{\prime}=$ $130^{\circ} \mathrm{C}$, the comprehensive specific frictional resistance corresponding to each flow rate can be solved, by which we can draw the curves of flow rate-Comprehensive specific frictional resistance as in Figure 9. 

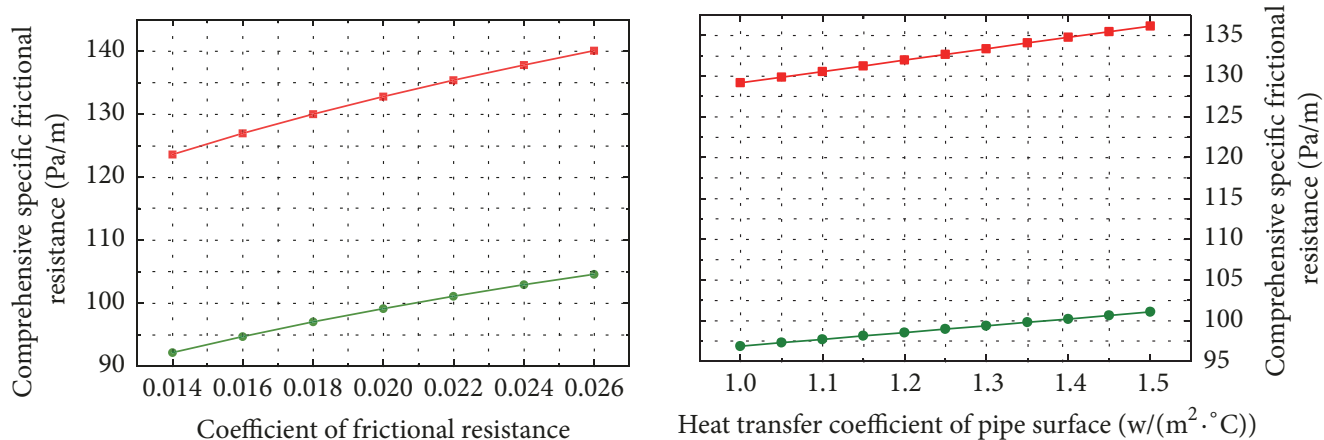

- Flow rate regulation

$\rightarrow$ Quantity regulation

Heat transfer coefficient of pipe surface $\left(\mathrm{w} /\left(\mathrm{m}^{2} \cdot{ }^{\circ} \mathrm{C}\right)\right)$

- Flow rate regulation

$\rightarrow$ Quantity regulation
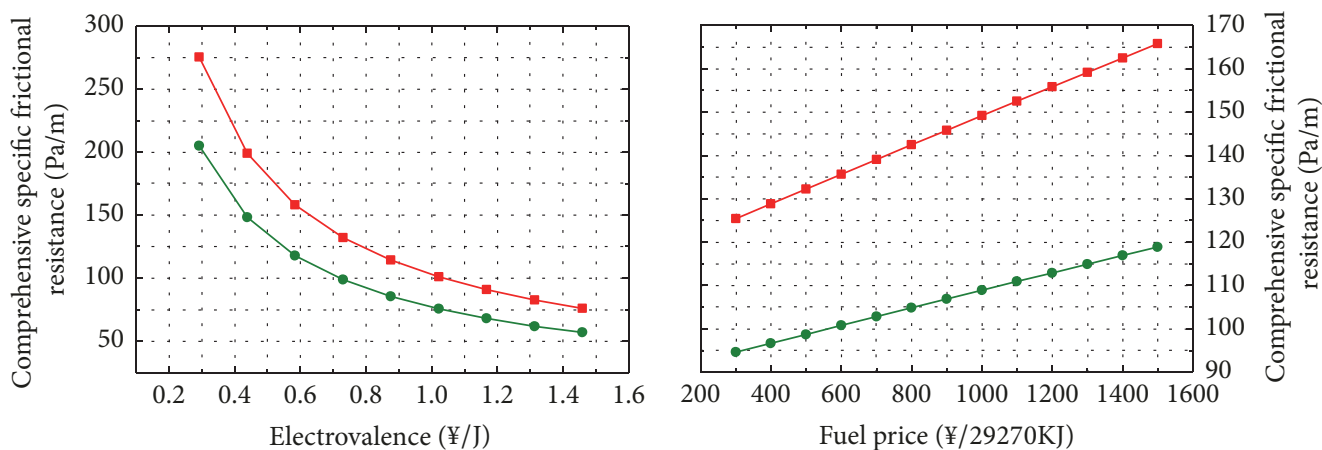

- Flow rate regulation

$\rightarrow$ Quantity regulation

- Flow rate regulation
$\rightarrow$ Quantity regulation
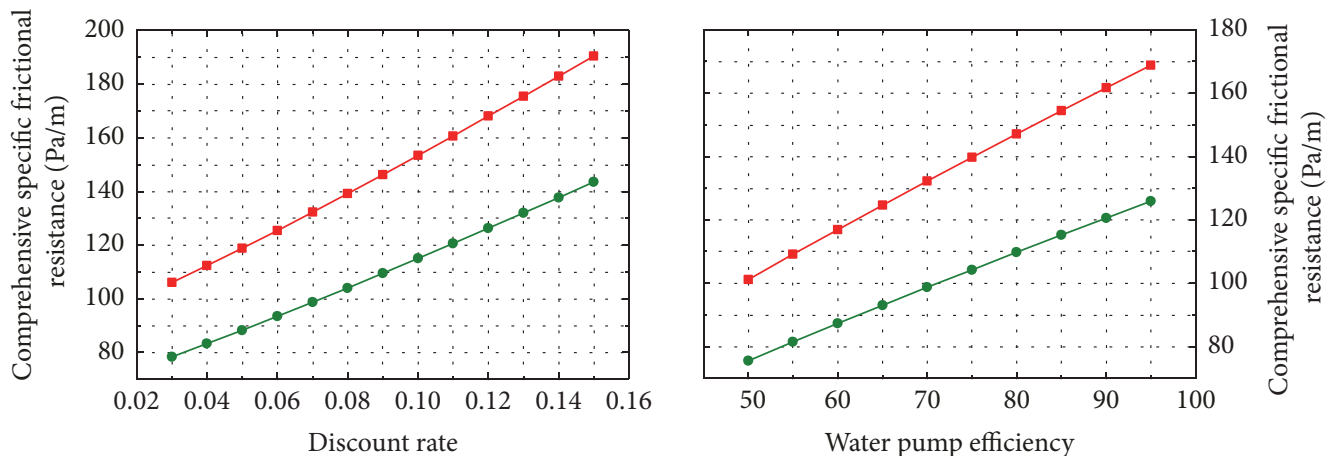

$=$ Flow rate regulation

$\rightarrow$ Quantity regulation

$\rightarrow$ Flow rate regulation

$\rightarrow$ Quantity regulation
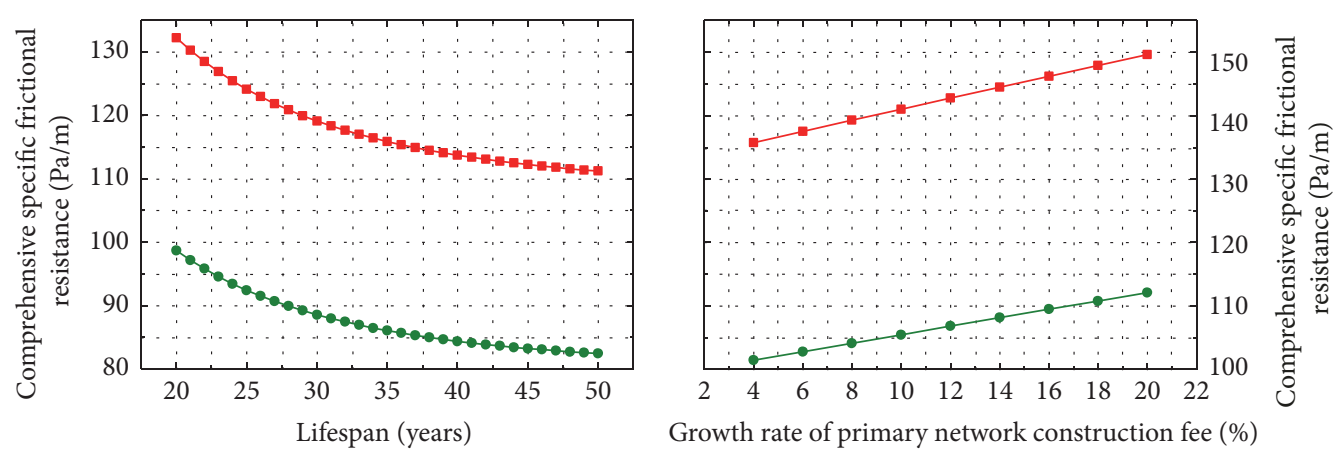

- Flow rate regulation

$\rightarrow$ Quantity regulation

Growth rate of primary network construction fee (\%)

- Flow rate regulation

$\rightarrow$ Quantity regulation

FIGURE 8: Effects of various factors on comprehensive specific frictional resistance. 
TABLE 3: Comparison table of economic effect evaluation indexes.

\begin{tabular}{|c|c|c|c|c|c|c|}
\hline $\begin{array}{l}\text { Schemes } \\
\text { Index }\end{array}$ & $\begin{array}{l}\text { Payback } \\
\text { Period } \\
\text { (years) }\end{array}$ & $\begin{array}{l}\text { Net Present } \\
\text { Value } \\
(¥ 10000)\end{array}$ & $\begin{array}{l}\text { Rate of Return on } \\
\text { Investment } \\
(\%)\end{array}$ & $\begin{array}{l}\text { Internal Rate of } \\
\text { Return } \\
(\%)\end{array}$ & $\begin{array}{c}\text { Present Value } \\
\text { Cost } \\
(¥ 10000) \\
\end{array}$ & $\begin{array}{l}\text { Initial } \\
\text { Investment } \\
(¥ 10000)\end{array}$ \\
\hline $\begin{array}{l}\text { Scheme one } \\
\text { (Comprehensive specific } \\
\text { frictional resistance) }\end{array}$ & 11.39 & 40872.73 & 39.13 & 11.7 & 32116.94 & 104463.1 \\
\hline $\begin{array}{l}\text { Scheme two } \\
\text { (Economic specific frictional } \\
\text { resistance) }\end{array}$ & 12.04 & 37460.97 & 34.15 & 11.1 & 34477.33 & 109679.8 \\
\hline
\end{tabular}

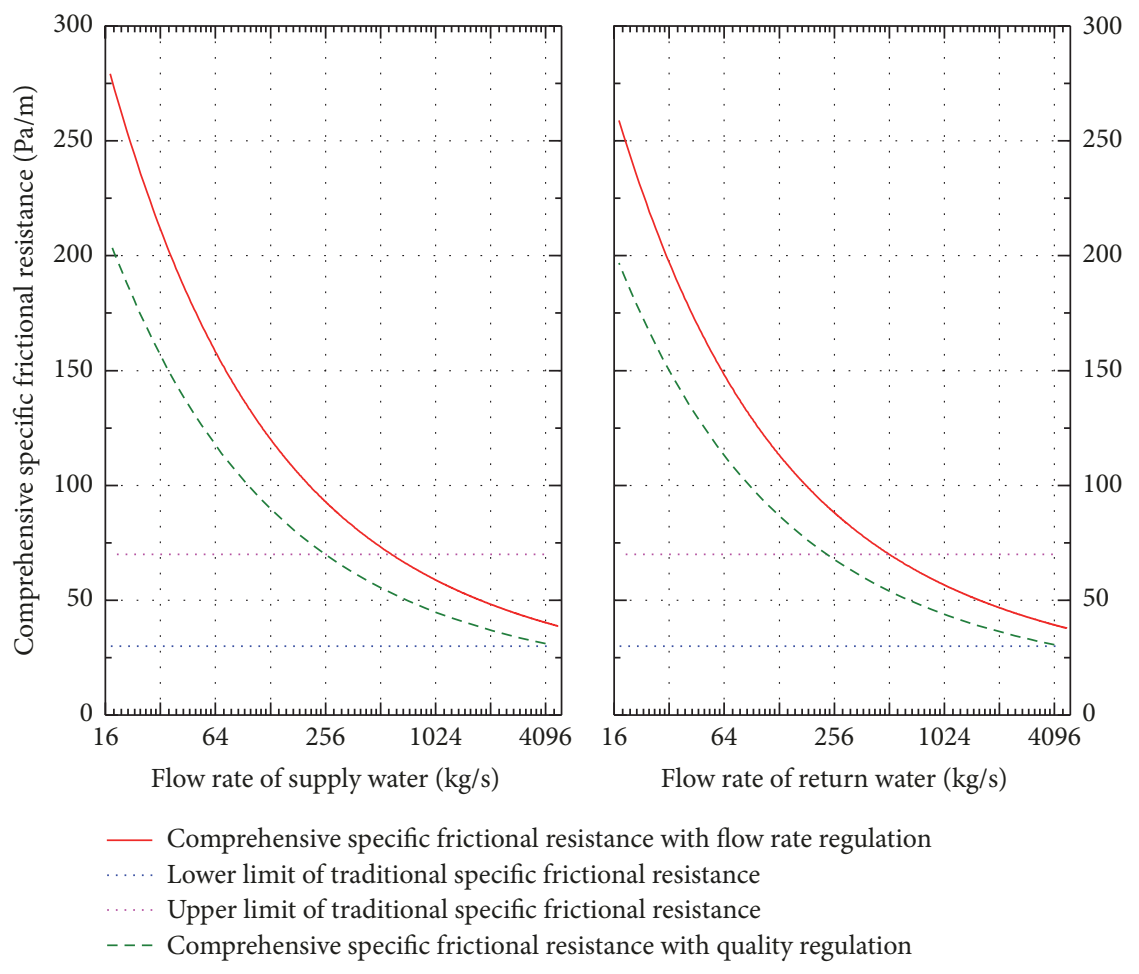

FIGURE 9: Supply and return water flow rate-comprehensive specific frictional resistance.

Some conclusions can be drawn from the Figure 9:

(1) Different from the traditional method, the concrete value of the comprehensive specific frictional resistance can be calculated for each pipe segment, rather than resulting from an arbitrary choice in the range of $30 \sim 70 \mathrm{~Pa} / \mathrm{m}$, so the method of comprehensive specific frictional resistance has a higher degree of refinement. In addition, the comprehensive specific frictional resistances are different for different pipe segments in a heating system, which reflects the pipe segment differences. Comprehensive specific frictional resistance decreases with an increase of design flow rate, and this decreasing trend slows down with the progressive increase in flow rate. Therefore, when the design flow rate of the pipe segment is in a certain range, the comprehensive specific frictional resistance is between $30 \sim 70 \mathrm{~Pa} / \mathrm{m}$, which is consistent with the traditional economic specific frictional resistance, but for the pipe segments beyond this range, it is unreasonable to determine the comprehensive specific frictional resistance according to the traditional method.

(2) Comparing the two images in Figure 9, there is little difference in the comprehensive specific frictional resistance between the water-supply pipes and the corresponding waterreturn pipes, but we still find that a small difference may lead to different diameters, such as in pipe segments 115 and $115^{\prime}$ or 122 and $122^{\prime}$ in Table 2.

(3) We know from Figure 9 that the comprehensive specific frictional resistance with flow rate regulation is bigger than it is with quality regulation for the same flow rate, and this difference increases with decreases in the design flow rate. Therefore, it is necessary to distinguish between different regulation modes regarding the issue of comprehensive specific frictional resistance.

(4) For the pipe segments with universal flow rate, comparing with the range of traditional economic specific 
frictional resistance of $30 \sim 70 \mathrm{~Pa} / \mathrm{m}$, the value of comprehensive specific frictional resistance is higher and can reach up to $200 \mathrm{~Pa} / \mathrm{m}$. There are three reasons for this: (1) the value of $30 \sim 70 \mathrm{~Pa} / \mathrm{m}$ was obtained from experience with directly connected heating networks in the past [8]. For indirectly connected heating networks, according to the experience of Nordic countries, the value of specific frictional resistance will be higher than the above specified value; (2) in recent years, the growth trend of electrovalence has been relatively flat, but the growth in pipe materials and pipe fittings has been large, resulting in an increase in specific frictional resistance; (3) for flow rate regulation, the calculation of comprehensive specific frictional resistance considers the change of the actual flow rate during operation. By this calculation, the computational electricity consumption is less than the electricity consumption calculated by design flow rate, so the value of comprehensive specific frictional resistance is greater than the traditional value.

\section{Conclusions}

In this paper, we put forward the concept of comprehensive specific frictional resistance, which aims to improve the precision degree of specific frictional resistance so as to promote the development of heating engineering. We provide a method to obtain the value of comprehensive specific frictional resistance by establishing a mathematical model, which is applicable to the optimization of pipe diameter in primary heating networks. Although the comprehensive specific frictional resistance has the disadvantage of a complex calculation process, it reflects the pipe segment differences, differentiates the different operation regulation modes, and takes into account the safety problems caused by pipe pressure. Therefore, it is of high practical value.

The ideal value of comprehensive specific frictional resistance is affected by the factors mentioned in this paper and also needs to be enriched and developed through further research.

\section{Conflicts of Interest}

The authors declare that there are no conflicts of interest regarding the publication of this article.

\section{References}

[1] H. V. Larsen, B. Bøhm, and M. Wigbels, "A comparison of aggregated models for simulation and operational optimisation of district heating networks," Energy Conversion and Management, vol. 45, no. 7-8, pp. 1119-1139, 2004.

[2] H. Shi, The theory research of economic friction of heating pipe network [M.S. thesis], Xi'an University of Architecture and Technology, Xi'an, China, 2013.

[3] C. Hong, "A brief analysis of the weighted mean specific frictional resistance," District Heating, vol. 41, pp. 49-53, 1992.

[4] A. Ge, C. Qiao, and Y. Zhao, "The relationship between range of heat-supply service and optimal specific frictional head loss," Energy Conservation, vol. 35, no. 12, pp. 18-21, 2015.
[5] M. Liu, R. Wu, and Q. Yang, “Transportation energy consumption and economical specific frictional resistance design of sewage heat pump system," Energy Conservation Technology, vol. 32, no. 188, pp. 487-491, 2014.

[6] Z. Wang, Z. Dong, and R. Wang, "Study of economic specific frictional resistance on hot water heating system for civil buildings," Architectural Science, vol. 26, no. 10, pp. 31-34, 2010.

[7] X. Li, P. Zhou, and M. Duan, "Calculation of optimal specific frictional head loss in condensate network," Gas and Heat, vol. 26, no. 3, pp. 59-62, 2006.

[8] P. He and G. Sun, Heating Project, China Architecture and Building Press, Beijing, China, 2000.

[9] Ministry of Housing and Urban-Rural Construction of the People's Republic of China, State Technical Method for Civil Building Project Design, China Planning Press, China.

[10] X. Sun, Research of the economic specific frictional resistance of primary network of hot water heating[M.S. thesis], Taiyuan University of Technology, Shanxi, China, 2010.

[11] J. Liu, "Analysis and calculation of economic specific frictional resistance in hot water heating network," Journal of Nanjing Institute of Architectural Engineering, vol. 15, no. 4, pp. 38-43, 1998.

[12] M. Manfren, P. Caputo, and G. Costa, "Paradigm shift in urban energy systems through distributed generation: Methods and models," Applied Energy, vol. 88, no. 4, pp. 1032-1048, 2011.

[13] C. Y. Xu and Q. Chen, "An entransy dissipation-based method for global optimization of district heating networks," Energy \& Buildings, vol. 48, no. 1, pp. 50-60, 2011.

[14] M. Bojic and N. Trifunovic, "Linear programming optimization of heat distribution in a district-heating system by valve adjustments and substation retrofit," Building and Environment, vol. 35, no. 2, pp. 151-159, 2000.

[15] J. Fu, Industrial Technology Economics, Tsinghua University Press, Beijing, China, 1996.

[16] F. Wu and F. Ye, Engineering Economics, China Machine Press, Beijing, China, 2007.

[17] S. Xu and Y. Jia, "The analysis of the operational regulation mode in the system of district heating," Journal of Hebei University of Engineering, vol. 25, no. 2, pp. 36-39, 2008.

[18] J. Chen, Research on energy saving of the operation adjustment mode of heating system [M.S. thesis], North China Electric Power University, Beijing, China, 2014.

[19] B. Babiarz, "An introduction to the assessment of reliability of the heat supply systems," International Journal of Pressure Vessels and Piping, vol. 83, no. 4, pp. 230-235, 2006.

[20] H. Boudali and J. B. Dugan, "Erratum: "A continuous-time Bayesian network reliability modeling and analysis framework" (IEEE Transactions on Realibility)," IEEE Transactions on Reliability, vol. 57, no. 3, p. 532, 2008.

[21] O. Fujiwara and A. U. De Silva, "Algorithm for reliability-based optimal design of water networks," Journal of Environmental Engineering (United States), vol. 116, no. 3, pp. 575-587, 1990.

[22] I. C. Goulter and A. V. Coals, "Quantitative approaches to reliability assessment in pipe networks," Journal of Transportation Engineering, vol. 112, no. 3, pp. 287-301, 1986.

[23] D. A. Savic and G. A. Walters, "Genetic algorithms for leastcost design of water distribution networks," Journal of Water Resources Planning and Management, vol. 123, no. 2, pp. 67-77, 1997.

[24] K. Vairavamoorthy and M. Ali, "Optimal design of water distribution systems using genetic algorithms," Computer-Aided 
Civil and Infrastructure Engineering, vol. 15, no. 5, pp. 374-382, 2000.

[25] X. Xia and L. Feng, "Analysis of the influence of absolute equivalent roughness," Shanghai Gas, vol. 54, no. 2, pp. 10-12, 2010.

[26] F. Chen, H. Yu, Z. Sun, and Y. Guo, "Determination of inner wall roughness of pipeline," Nature Gas and Oil, vol. 25, no. 6, pp. 8-10, 2007.

[27] Y. Dou and X. He, "Calculation method for hydraulic resistance of pipe," Journal of Hydraulic Engineering, vol. 40, no. 7, pp. 2831, 1995 .

[28] M. Xu and P. He, "Determination method of heating load continuity diagram," District Heating, vol. 4, no. 1, pp. 3-10, 1986.

[29] L. Yang and H. Tao, "Engineering experimental research on energy-saving of economical flow velocity and pipe diameter optimization in water supply system," Water \& Wastewater Engineering, vol. 35, pp. 334-336, 2009.

[30] H.-B. Jiang, "Cost function, optimal pipe diameter and economical flow velocity of water supply system," Harbin Gongye Daxue Xuebao/Journal of Harbin Institute of Technology, vol. 36, no. 1, pp. 84-90, 2004.

[31] Z. Chen, Z. Cai, and C. Qian, Chemical Engineering Thermodynamics, Chemical Industry Press, China, 2015.

[32] J. Chen, Real Function Theory, Science Press, China, 1978. 


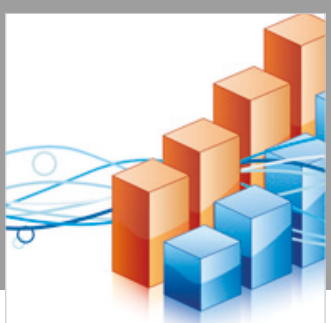

Advances in

Operations Research

\section{-n-m}
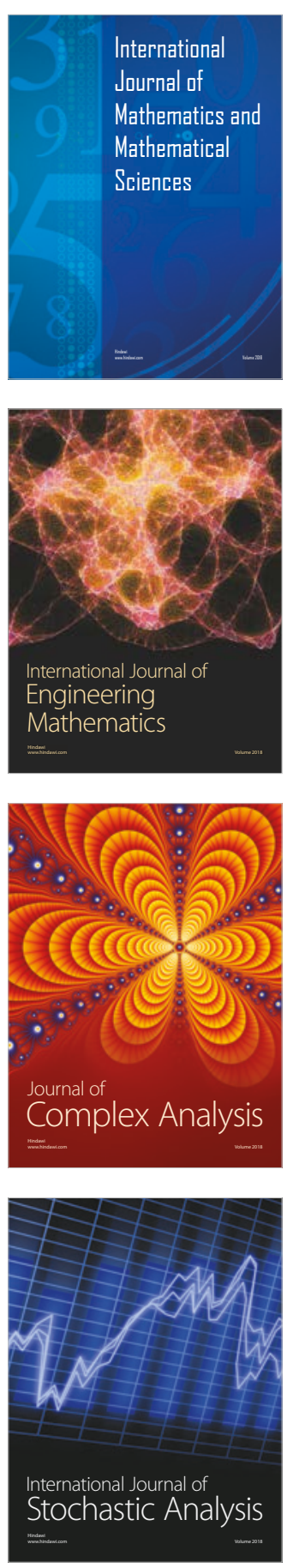
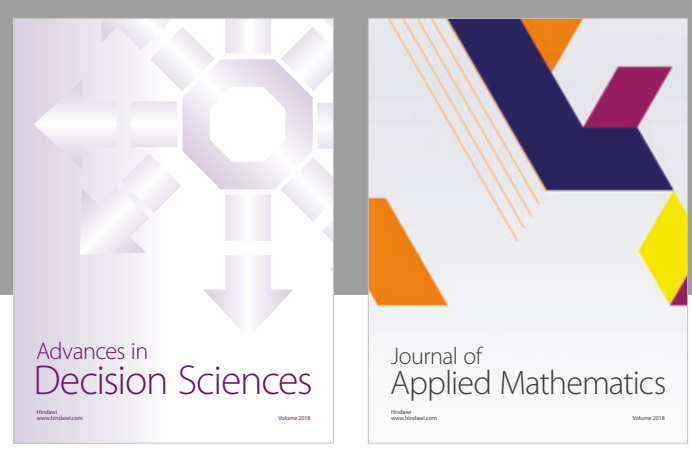

Journal of

Applied Mathematics
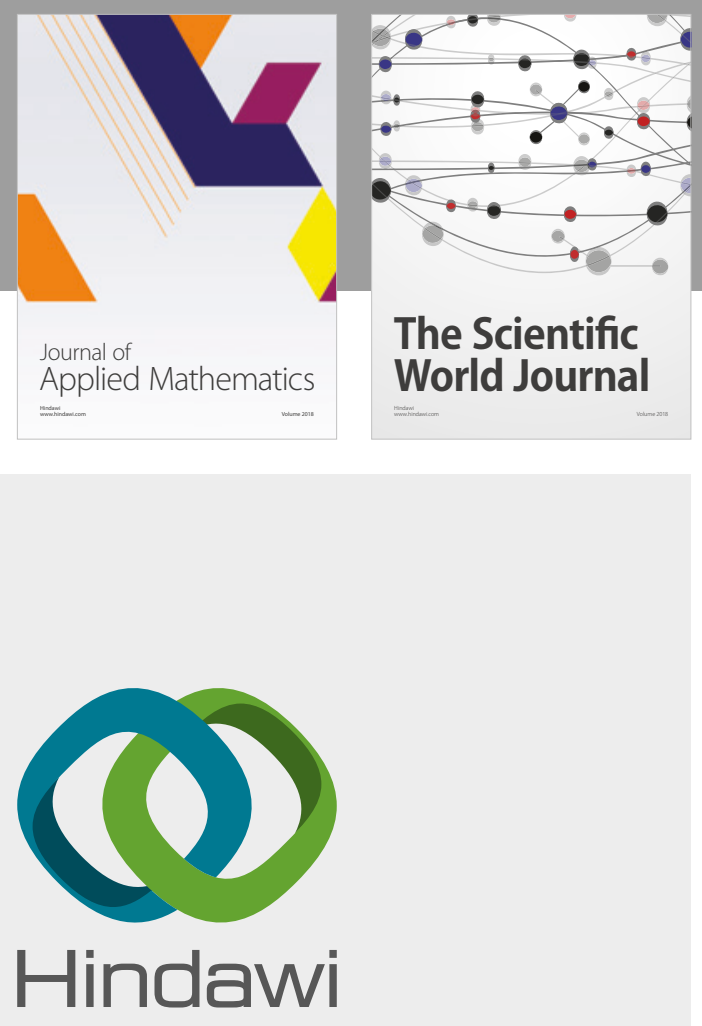

Submit your manuscripts at

www.hindawi.com

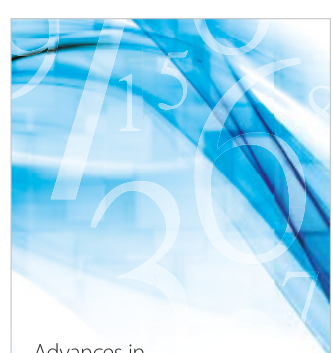

Advances in
Numerical Analysis
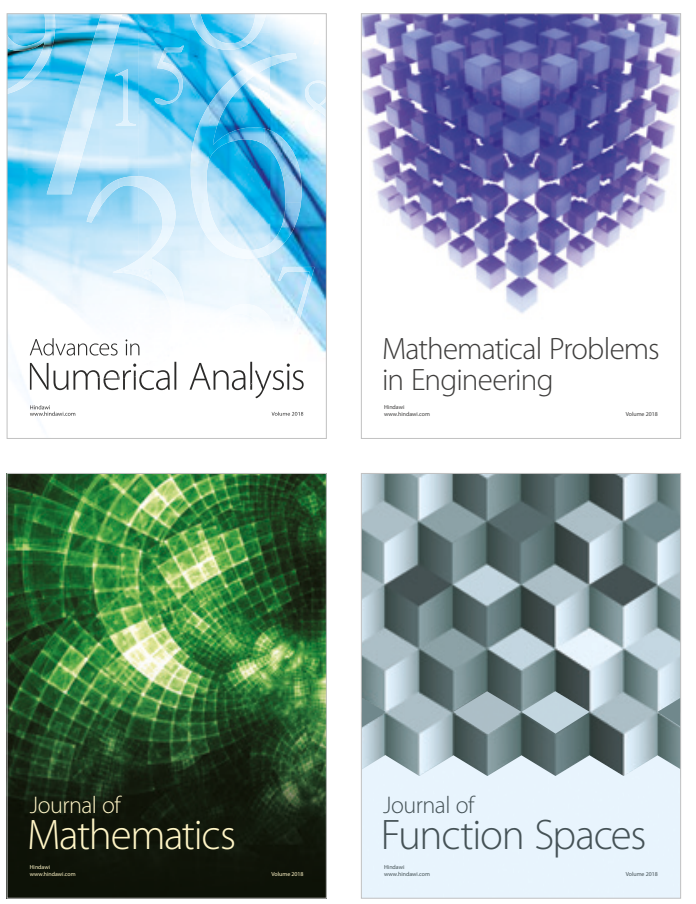

Mathematical Problems in Engineering

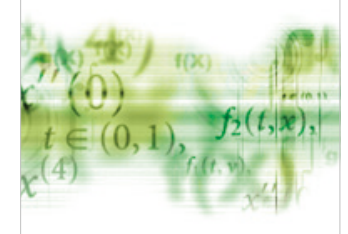

International Journal of

Differential Equations

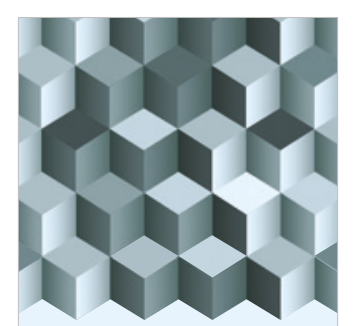

Journal of

Function Spaces

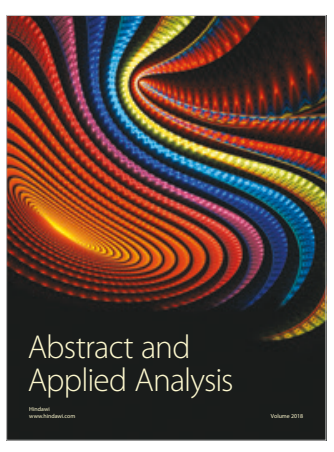

The Scientific

World Journal

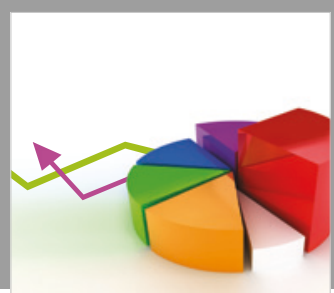

Journal of

Probability and Statistics
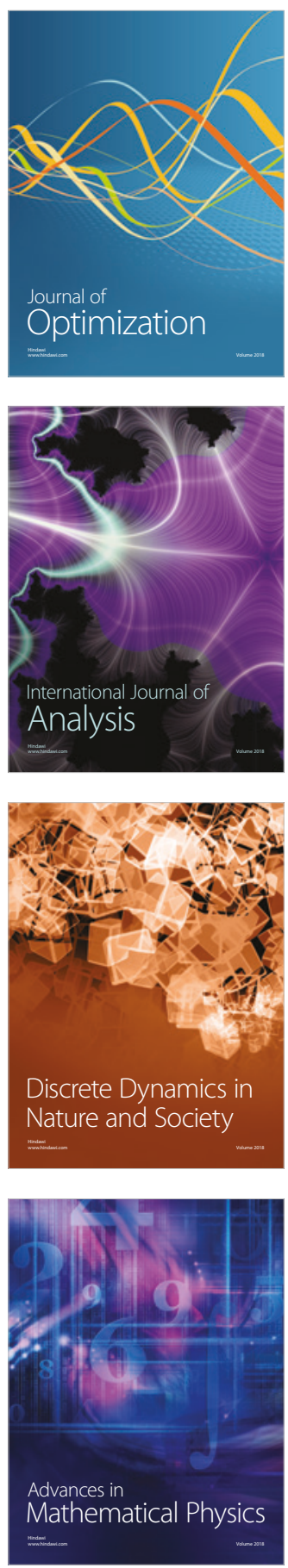